\title{
Aerodynamic Study of Wind Flow through a Lattice Tower of Angular Section Profiles, Using Computational Fluid Dynamics
}

\author{
André COSTA ${ }^{\mathrm{a}}$, Fábio PAIVA ${ }^{\mathrm{b}}$, Rui BARROS ${ }^{\mathrm{c},{ }^{*}}$
}

Faculty of Engineering of the University of Porto, Civil Engng Dept, Structural Division, Portugal

${ }^{a}$ costa.andreivan@gmail.com, ${ }^{b}$ fmp@fe.up.pt, ${ }^{c,}{ }^{*}$ rcb@fe.up.pt

${ }^{*}$ Corresponding author

Keywords: Lattice Towers, Wind Flow, CFD.

\begin{abstract}
The advancement of technological society in general has stimulated in various fields, such as aeronautical civil mechanical naval and offshore engineering, a need to look for more sophisticated structural solutions. In many cases these solutions resort to lattice towers that, in order to meet several functional requirements, result in structures with ever more complex geometries. As such Computational Fluid Dynamics (CFD) arises as a tool to achieve a quick and economic analysis of wind flow around these structures, thereby overcoming limitations imposed by current codes that do not cover all structure typologies and sectional differences. Thus this work performs an aerodynamic study of a lattice tower, where the displacements and reactions caused by wind action according to Eurocode 1 (EN 1991-1-4) are calculated by the software Autodesk Robot Structural Analysis and compared with results of a CFD analysis.
\end{abstract}

\section{Introduction}

The objective of this work was part of the master of science dissertation of the first co-author under supervision of the third co-author, consisting in the study of wind flow across sections of a space lattice tower [1].

The computational fluid dynamics, usually referred to as CFD, is the analysis of systems involving fluid flow, heat transfer and associated phenomena such as chemical reactions by means of computer simulations [2]. The physical aspects of any fluid flow are governed by three fundamental principles and a mathematical equation: (a) Principle of mass conservation; (b) Principle of momentum conservation; (c) Equation of state; (d) Principle of energy conservation.

In many applications it is possible to simplify the problems in fluid dynamics. In cases where the flow velocity is much lower than Mach 1, more precisely when the ratio between the flow velocity and the speed of sound is less than 0.3 (according to [3], as it is the case in question), then it can be considered that fluid is incompressible so that it is not necessary the consideration of temperature. Thus, only three principles govern fluid flow: (a) Principle of mass conservation; (b) Principle of momentum conservation; (c) Principle of energy conservation.

The equations corresponding to the principles presented were discretized using the method of finite volumes.

\section{Navier-Stokes Equations}

These basic principles can be expressed in terms of mathematical equations, which usually take the form of partial differential equations [4]. In the case of dynamic equilibrium equations, the equations that will be used in this study are the Navier-Stokes equations (Equations 1-3).

$$
\begin{aligned}
& \frac{\partial u}{\partial t}+u \frac{\partial u}{\partial x}+v \frac{\partial u}{\partial y}+w \frac{\partial u}{\partial z}=-\frac{1}{\rho} \frac{\partial p}{\partial x}+\frac{\mu}{\rho}\left(\frac{\partial^{2} u}{\partial x^{2}}+\frac{\partial^{2} u}{\partial y^{2}}+\frac{\partial^{2} u}{\partial z^{2}}\right) \\
& \frac{\partial v}{\partial t}+u \frac{\partial v}{\partial x}+v \frac{\partial v}{\partial y}+w \frac{\partial v}{\partial z}=-\frac{1}{\rho} \frac{\partial p}{\partial y}+\frac{\mu}{p}\left(\frac{\partial^{2} v}{\partial x^{2}}+\frac{\partial^{2} v}{\partial y^{2}}+\frac{\partial^{2} v}{\partial z^{2}}\right)
\end{aligned}
$$




$$
\frac{\partial \mathrm{w}}{\partial \mathrm{t}}+\mathrm{u} \frac{\partial \mathrm{w}}{\partial \mathrm{x}}+\mathrm{v} \frac{\partial \mathrm{w}}{\partial \mathrm{y}}+\mathrm{w} \frac{\partial \mathrm{w}}{\partial z}=-\frac{1}{\mathrm{p}} \frac{\partial \mathrm{p}}{\partial \mathrm{z}}+\frac{\mu}{\mathrm{p}}\left(\frac{\partial^{\mathrm{x}} \mathrm{w}}{\partial \mathrm{x}^{\mathrm{x}}}+\frac{\partial^{\mathrm{x}} \mathrm{w}}{\partial \mathrm{y}^{2}}+\frac{\partial^{\mathrm{x}} \mathrm{w}}{\partial \mathrm{z}^{2}}\right)
$$

Here it is assumed that: the fluid is a Newtonian fluid, that is, a fluid for which each component of the shear stress is proportional to the velocity gradient in the direction normal to such component, such as occurs with water and air; the viscosity, $\mu$, is constant; and the component of the gravitational force, self-weight, was incorporated into the pressure, $\mathrm{p}$, in the corresponding direction [5].

\section{RANS (Reynolds Averaged Navier-Stokes) Turbulence Models}

The turbulence model that will be discussed is a model-based approach k- $\varepsilon$ model that will be used in the modeling of the next chapter; it belongs to the class of models with two equations, called RANS (Reynolds Averaged Navier-Stokes). It is a model that solves the Navier-Stokes equations in a statistical manner and is based on the transport equations for the kinetic energy (controlled by parameter $\mathrm{k}$ ) and on the dissipation rate of turbulence (controlled by parameter $\varepsilon$ ). It is used for virtually all cases of flow, because of its robustness and a relatively quick resolution and accuracy even in cases with a large range of Reynolds number variation. The turbulence models

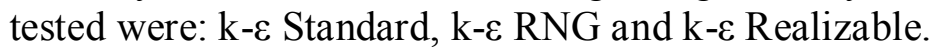

\section{Aerodynamic Study of a Lattice Tower}

The steel latticed towers (like the ones used as transmission towers or as communications towers) can have various configurations in plan and along their height. In the large majority, such towers are lattice structures with square or rectangular bases, consisting of thin-walled elements, usually angular section profiles or (less frequently) metal tubes (of circular hollow sections CHS, of rectangular RHS or of square hollow sections SHS).

The lattice tower under study was designed to resist the action of the wind in the area $\mathrm{A}$ of the Portuguese national territory and for a terrain of type II. To calculate the generalized forces and deformations caused on the lattice tower by the regulatory design conditions of Eurocode 1 [6], it was considered the fundamental combination of actions associated with the Ultimate Limit State (ULS) and given by $1.35 G_{k}+1.5 W_{k}$, where it was considered self-weight of the structure and of the mass located at the top as permanent actions with their characteristic values $\left(G_{k}\right)$ and wind as the variable action with its characteristic value $\left(W_{k}\right)$.

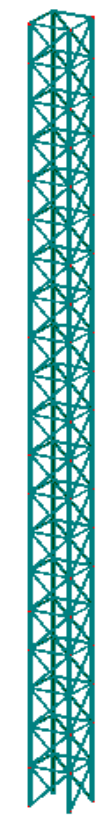

(a)

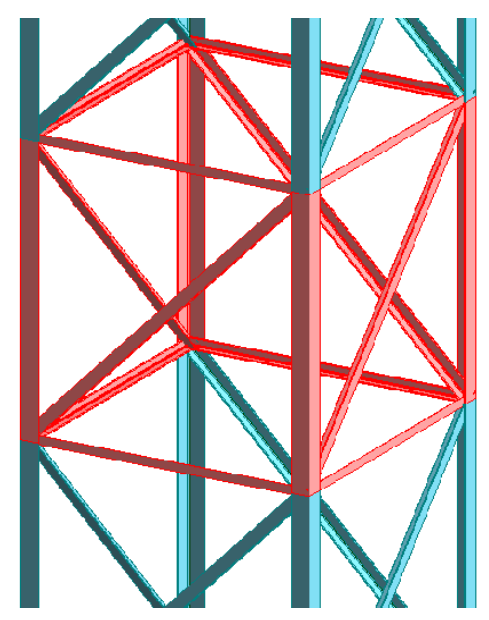

(b)

Fig. 1 Total (a) and Partial (b) View of the Lattice Tower and of its Main Elements and Bracing 
For this numerical aerodynamic study it was adopted a tower with a square base, as shown in Fig. 1 , consisting of metal profile elements of thin wall angular sections. The base of the lattice tower has a width of $1 \mathrm{~m}$ and the maximum height of the tower is equal to $20 \mathrm{~m}$. At the top of the tower was placed a mass of 2000 kilograms, thereby not conditioned in their further use, in order to obtain a natural frequency of the structure so that its behavior and response would be constrained and controlled by the wind action (among other possible regulatory actions).

The CFD analysis was performed using software SolidWorks through the Flow Simulation option. The options performed for the flow simulation were based on a calibration model of part of the structure: a fabrication module with 1 meter high. For such module, the pressures and generalized forces generated by CFD analysis of wind flow were compared with the ones resulting from a structural analysis of the lattice tower based upon the specifications in Eurocode 1 (namely EN 1991-1-4 [6] ).

Subsequently a CFD analysis was held for the entire structure, which revealed the pressures generated in the windward side of the tower (Fig. 2).
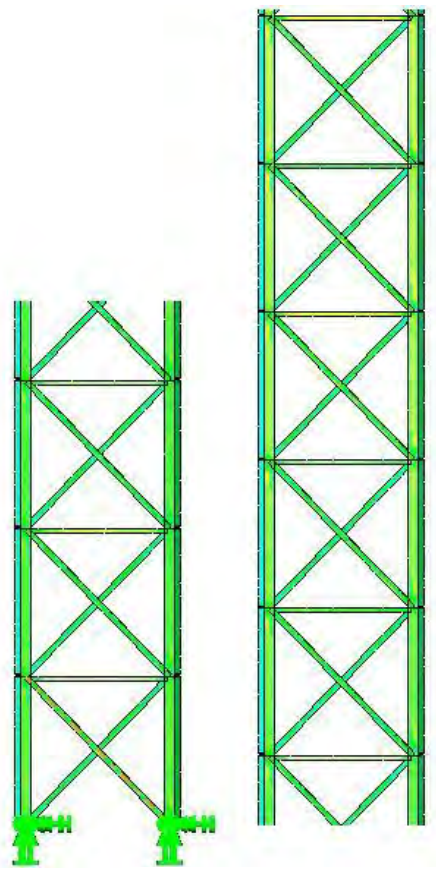

$14,5-20[\mathrm{~m}]$
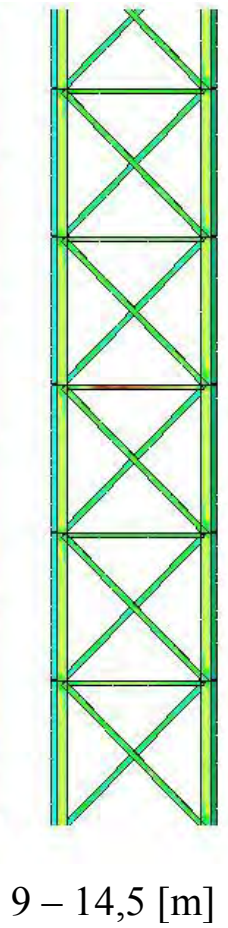

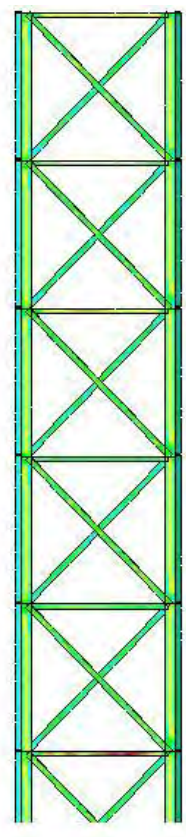

$3,5-9[\mathrm{~m}]$

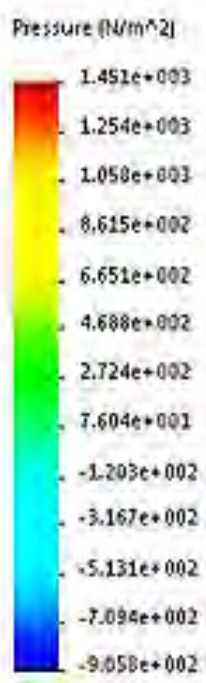

$0-3,5[\mathrm{~m}]$

Fig. 2 View of the Pressures on the Windward Face of the Structure

\section{Analysis of Deformation and Reactions of the Structure}

The analysis of deformation and reactions of the entire structure was based upon a static analysis of the pressures generated by the wind in the structure, taken from the CFD analysis, and was compared with the same static analysis, with the generalized forces resulting from the calculation of average wind actions according to the Eurocode 1 (EN 1991-1-4 [6] ).

In Fig. 3 are presented the results of the displacements obtained by software SolidWorks and Robot. In Table 1 and Table 2 are presented the reactions on the supports of structure, also corresponding to SolidWorks and Robot software.

Tab.1 Reactions on Supports (SolidWorks)

\begin{tabular}{cccc}
\hline Apoios & FX $(\mathrm{KN})$ & FY $(\mathrm{KN})$ & FZ $(\mathrm{KN})$ \\
\hline 1 & $-2,79$ & $-0,02$ & $-32,78$ \\
\hline 2 & 0,03 & 0,02 & 32,78 \\
\hline 3 & 0,03 & 0,02 & $-32,78$ \\
\hline 4 & $-2,79$ & $-0,02$ & 32,78 \\
\hline
\end{tabular}

Tab. 2 Reactions on Supports (Robot)

\begin{tabular}{cccc}
\hline Apoios & FX(KN) & FY $(\mathrm{KN})$ & FZ $(\mathrm{KN})$ \\
\hline 1 & $-1,53$ & $-20,70$ & 0,046 \\
\hline 2 & $-0,08$ & 17,60 & $-0,02$ \\
\hline 3 & $-0,09$ & $-17,70$ & 0,21 \\
\hline 4 & $-1,67$ & 20,30 & 0,04 \\
\hline
\end{tabular}



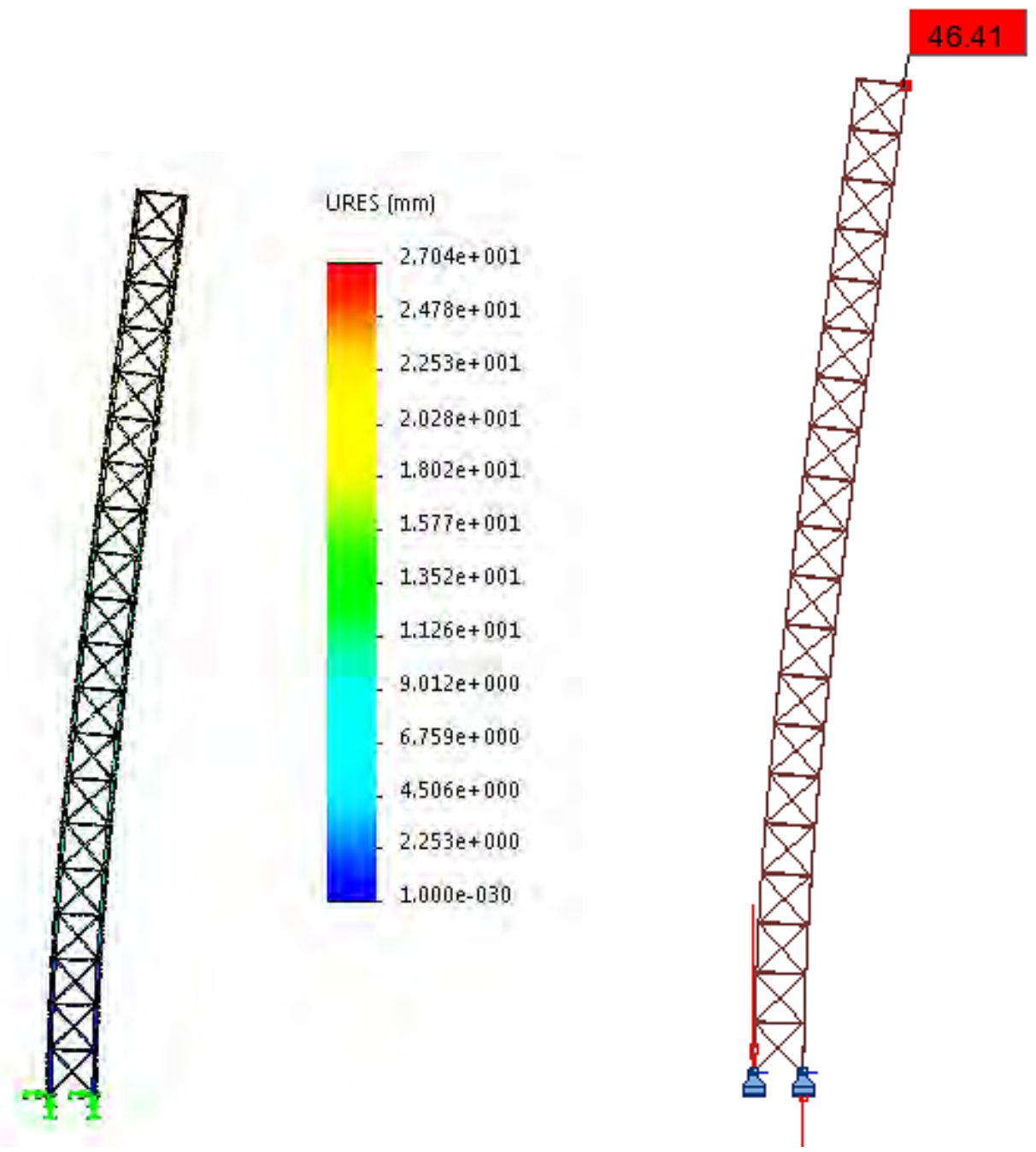

Fig. 3 Displacements Obtained by Software Solid Works (left) and by software Robot (right)

By observing the displacements obtained in the analysis by Robot software (Fig. 3), it appears that these have displacement values around $70 \%$ higher than the displacements obtained by SolidWorks software. This difference is also seen in the values of the vertical and horizontal reactions obtained (Tables 1 and 2). This difference can partly be explained by the conservative method that was used in modeling the wind action on the structure by Robot software, where the wind actions are concentrated at the nodes of the structure. This type of method is not followed for the CFD analysis, where the pressures are distributed evenly across all the bars of the structure (Fig. 2).

Still, one factor that may justify this difference in results is the coefficient of force obtained by the CFD analysis.

In fact, this work comes in the sequel of a complimentary paper about the determination of drag coefficients of angular sections profiles, isolated or in group, using computational fluid dynamics [7] with important conclusions on drag coefficients and characterization of wind flow around angular open sections as those of profile members used in lattice towers.

\section{Conclusion}

After analysis of the results obtained by the considered lattice tower under a wind flow, evaluated by a CFD analysis [1] and by the application of the wind action on the tower according to the Eurocode 1 regulations under EN 1991-1-4 [6], it was concluded that the latter code standard [6] presents conservative results evaluated in excess of the reality. This fact also enables CFD analysis to co nstitute an important theoretical and practical modeling tool for optimization of structures 
under wind flow, provided it is duly validated by experimental tests, preferably at full scale, to achieve a sufficient degree of confidence that allows face this modeling tool with more certainty and exactness.

\section{Acknowledgement}

The authors acknowledge the support from the project "VHSSPOLES - Very High Strength Steel Poles" (Faculty of Engineering of the University of Porto, reference 21518).

\section{References}

[1]A.I.A. Costa, Estudo do escoamento do vento através de uma torre treliçada espacial, Master of Science dissertation (in Portuguese), Faculty of Engineering of the University of Porto, Porto Portugal, 2014.

[2]H.K. Versteeg and W. Malalasekera, An introduction to computational fluid dynamics: the finite volume method, Pearson Education, 2007.

[3]J.H. Ferziger and M. Peric, Computational methods for fluid dynamics, Vol.3, Springer, Berlin, 2002.

[4]J. Novais-Barbosa, Mecânica de Fluidos e Hidráulica Geral, Vol.1, Porto Editora, Porto, 1986.

[5]M.B. Abbot and D.R. Basco, Computational fluid dynamics - An introduction for engineers, NASA STI/Recon Technical Report A, 1989.

[6]Instituto Português da Qualidade, Eurocódigo 1 - ações em estruturas Parte 1-4 ações gerais. Ação do vento (in Portuguese), NP EN 1991-1-4:2010/A1:2010, Caparica, 2010.

[7]A. Costa, F. Paiva, and R. Barros, On the Determination of Drag Coefficients of Angular Sections Profiles, Isolated or in Group, using Computational Fluid Dynamics, Paper submitted to the 2014 International Conference on Mechanics and Civil Engineering (ICMCE2014), December 13th-14th Wuhan - China, Atlantis Press, 2014 (in-press). 